\title{
COISAS QUE SÓ SE DIZEM EM LATIM: A PRESENÇA DE BOILEAU NA CRÔNICA DE MACHADO DE ASSIS
}

\author{
CALLIPO, Daniela Mantarro ${ }^{1}$
}

\begin{abstract}
RESUMO: No século XIX, literatura e jornalismo não estabeleciam uma fronteira rígida. Ambas as práticas se confundiam e, por essa razão, as notícias podiam trazer elementos ficcionais e os poemas, abordar fatos deveras ocorridos. Nesse período, a crônica era um gênero estimado do leitor e produzido em grande quantidade por colaboradores que contavam os acontecimentos ocorridos de forma leve e divertida. Gênero híbrido, mistura de realidade e ficção, a crônica é rica e despretensiosa, colada ao tempo e eterna, satírica e poética. Ela parte de um fato real, mas não é notícia; constitui-se por meio da paródia e da sátira, mas não é conto, nem romance. O jornal do século XIX acolhe todos esses gêneros democraticamente, criando uma "literalização ambígua". Machado de Assis foi um grande cronista e descreveu episódios vividos pela sociedade fluminense oitocentista, contando anedotas políticas, criticando comportamentos que julgava inaceitáveis, sempre com humor e ironia. Pretende-se analisar, neste artigo, a presença do clássico Boileau na crônica machadiana que trata do uso polêmico de anquinhas. Para se compreender a presença do elemento clássico na crônica machadiana, recorreu-se aos estudos de Thérenty (2007) e Kalifa (2011), pois esses teóricos auxiliam no entendimento da porosidade da crônica.
\end{abstract}

PALAVRAS-CHAVE: Boileau, crônica de Machado de Assis, moda feminina, Vênus Calipígia

\section{THINGS THAT ARE ONLY SAID IN LATIN: THE PRESENCE OF BOILEAU IN THE CHRONICLE OF MACHADO DE ASSIS}

\begin{abstract}
In the nineteenth century, literature and journalism blended into each other quite a bit. Both practices were constantly mixed up and, for that reason, news would often carry fictional elements and poems would approach real life events. In this period, chronicles were a genre in Literature very

\footnotetext{
1 Docente de Língua e Literatura Francesa da UNESP, Campus de Assis, Doutora em Língua e Literatura Francesa pela Universidade de São Paulo, Pós-Doutora em Teoria Literária pela Unicamp. E-mail: danielacallipo@gmail.com
} 
well liked by the public and vastly produced by writers associated to the news, who reported the events in a light and fun way. A hybrid genre that mixes reality and fiction, chronicles are rich and unpretentious, strongly attached to time and eternal, satirical and poetic. Literature of that genre was based in a real fact, but it wasn't considered a source of news; had elements of parody and satire, but is neither a tale, or a romance. Newspapers from the 19th century carried a selection of all genres, not giving much importance to labels, creating an "ambiguous literalization”. Machado de Assis was a great chronist and described several episodes lived by the people of Rio de Janeiro in the 19th century, writing political anecdotes and criticising behaviours deemed by him as unnaceptable, filled with humor and irony. This article's aim is to analyse the presence of the classic Boileau in Machado's chronicle about the polemic use of bum pads. To comprehend the presence of the classical element in Machado's chronicles, I've recurred to the studies of Thérenty (2007) and Kalifa (2011), since these academics have helped in the understanding of the chronicle's porosity.

KEYWORDS: Boileau, chronicles of Machado de Assis, women's clothing, Venus Callipyge

No século XIX, literatura e jornalismo não estabeleciam a fronteira rígida que conhecem hoje. Ambas as práticas se confundiam e o escritor de romances era o mesmo que publicava poemas e tecia comentários acerca de política e economia. Por essa razão, as notícias podiam trazer elementos ficcionais e os poemas, abordar episódios deveras ocorridos. Para Miceli,

Toda a vida intelectual era dominada pela grande imprensa que constituía a principal instância de produção cultural da época e que fornecia a maioria das gratificações e posições intelectuais. Os escritores profissionais viam-se forçados a ajustar-se aos gêneros que vinham de ser importados da imprensa francesa: reportagem, a entrevista, o inquérito literário e, em especial, a crônica. (MICELI, 1977, p.15)

Nesse período, a crônica era um gênero estimado pelo leitor e produzido em grande quantidade por colaboradores que contavam os acontecimentos ocorridos na semana ou na quinzena de forma leve e divertida. Gênero híbrido, mistura de realidade e ficção, a crônica é rica e despretensiosa, colada ao tempo e eterna, satírica e poética. Ela parte de um fato real, mas não é notícia; constitui-se por meio da paródia, da sátira, de elementos poéticos e até mesmo de metalinguagem, mas não é romance folhetim, do qual se aparta para constituir sua própria 
individualidade. O jornal do século XIX acolhe todos esses gêneros democraticamente, criando uma "literalização ambígua" (THÉRENTY, 2007, p. 20)

Machado de Assis foi um grande cronista, publicando cerca de seiscentas crônicas ao longo de quarenta anos de produção jornalística. Ele seguiu os passos de seus predecessores Alencar e Macedo, descrevendo episódios vividos pela sociedade fluminense oitocentista, contando anedotas políticas, criticando comportamentos que julgava inaceitáveis, sempre com humor e ironia. Atuais, suas crônicas podem continuar a ser lidas e apreciadas, porque a sociedade do século XXI muito se assemelha àquela do XIX, no tocante aos problemas enfrentados e às discussões promovidas.

Uma crônica devia ser leve e divertida e, por mais bem escrita que fosse, tinha vida curta, pois habitava o periódico que seria lido e descartado no dia seguinte ou, com sorte, uma semana depois. Também atingia poucos leitores, já que o número de analfabetos chegava a $80 \%$ da população do Brasil entre 1892 e 1920, segundo os dados dos censos brasileiros. ${ }^{2}$ Em 1876, um ano após o primeiro número do jornal Gazeta de Notícias ser publicado, Machado de Assis já havia comentado: “A nação não sabe ler. Há só 30\% dos indivíduos residentes neste país que podem ler; desses uns 9\% não leem letra de mão. 70\% jazem em profunda ignorância." (ASSIS, 2008. p. 344). A informação, como visto, não é exata, mas oferece um panorama do número restrito de leitores alcançados pelos periódicos. Desse modo, é preciso considerar com cautela a afirmação de Sodré (1999, p. 224): “[a] Gazeta de Notícias era, realmente, jornal barato, popular, liberal, vendido a 40 réis o exemplar". Popular, aqui, não tem o sentido que lhe atribuímos hoje, sobretudo se for levado em conta que, naquele período, havia um "círculo limitado dos leitores" (GUIMARÃES, 2004, p. 107).

Esse círculo era formado por letrados privilegiados que conheciam bem a produção nacional e a estrangeira, mais especificamente a francesa. A eles, portanto, eram dirigidas as crônicas que Machado de Assis escrevia e, ao inserir citações eruditas em português, francês, inglês e italiano em textos que deveriam ser leves e jocosos, Machado tinha a certeza de ser compreendido.

Por essa razão, na crônica que será analisada aqui, publicada no periódico fluminense Gazeta de Notícias, a presença do clássico Boileau não causa estranheza, pois o leitor da seção "Balas de Estalo", com a qual Machado de Assis colaborou entre 1883 e 1886, sob o

2 BRASIL, Recenseamento Geral do Brasil 1920. Rio de Janeiro, 1920. v.4, pt.4: população. Disponível em: https://biblioteca.ibge.gov.br/visualizacao/livros/liv6478.pdf. Acesso: 12 de maio de 2020. 
pseudônimo de Lélio, estava habituado à presença da literatura estrangeira. Respeitando uma norma seguida por todos os outros colaboradores da seção, Machado também se serviu de um pseudônimo. Para R. Magalhães Jr. (ASSIS, 198-, p. 13), o nome Lélio foi retirado de uma personagem da peça L'Étourdi, de Molière, escrita entre 1653 e 1655: filho de Pandolfe, Lélie é apaixonado pela bela escrava Célie. Estouvado, impulsivo e atrapalhado, ele estraga os dez planos preparados por seu valete Mascarille para ajudá-lo em sua conquista. Segundo Callipo (2008), entretanto, é preciso considerar a existência de uma personagem da "comedia dell'arte", cujo nome é Lélio. Presente no teatro italiano escrito entre os séculos XVI e XVII, o aventureiro romanesco surgirá em 1620 em Lelio bandito, de Andreini, será retomado em 1750 por Goldoni e em duas peças de Marivaux: La Surprise de l'amour, de 1722 e Le Prince travesti, de 1724. Machado acrescenta ao nome Lélio um sobrenome bem brasileiro e ele passa a se chamar "Lélio dos Anzóis Carapuça”, conforme se verifica na crônica de 17 de janeiro de 1885, em que ele escreve seu testamento: "Eu, Lélio dos Anzóis Carapuça, estando em meu perfeito juízo, determinei escrever este testamento, para o fim de deixar expressas as minhas últimas vontades, que espero sejam cumpridas, como se presente fosse."3

Publicada diariamente na segunda página da Gazeta de Notícias, a divertida seção "Balas de Estalo" contava com vários colaboradores, como Valentim Magalhães e Ferreira de Araújo, este último, um dos fundadores do periódico. Ali, discutiam-se política e economia, tratava-se de música e literatura, comentavam-se os faits divers, misturando-se expressões coloquiais, citações eruditas, frases em latim ou em línguas estrangeiras, canções de roda e ópera.

A crônica que interessa mais de perto foi publicada em $1^{\circ}$ de setembro de 1884 e inicia com algumas reflexões acerca da exposição de Belas Artes, exposição esta que iria se prolongar até novembro daquele ano e para a qual contribuíram muitos pintores e escultores renomados.

A inauguração da Mostra teve lugar em 24 de agosto e contou com a presença do Imperador, do Conde e da Condessa d'Eu, recebidos pelo então diretor da Academia, Nicolau Tolentino. A Gazeta de Notícias deu destaque ao evento, com uma reportagem de primeira página. O periódico informou que a família Imperial ali esteve por cerca de duas horas e pôde apreciar "trabalhos de bastante merecimento". ${ }^{4}$

\footnotetext{
3 Gazeta de Notícias, jan.1885, p. 02.

${ }^{4}$ Gazeta de Notícias, 24/08/1884, p. 01.
} 
A partir do dia 26 de agosto, o jornal começou a publicar, sempre na primeira página, a coluna intitulada "Belas Artes", assinada por L. S., sigla de Lulu Sênior, pseudônimo de Ferreira de Araújo. A cada dia, o articulista escolhia um expositor e dissertava sobre sua obra e as impressões que esta lhe causara: Abigail de Andrade, Firmino Monteiro, Aurélio de Figueiredo, Thomaz Driendi foram comentados e analisados por Lulu Sênior. O diretor do jornal não se conformava, porém, com o descaso do high-life em não visitar a mostra. Na coluna do dia 09 de setembro, ele desabafa:

Estou meio escamado com o high-life que, aliás, pouco se importa com isso, porque já me pregou uma peça a mim e mais ainda à direção da Academia que lhe reservou um dia da semana:

Quinta-feira passada, high-life ficou em casa ou andou pela Rua do Ouvidor $[\ldots]^{5}$

Indignado, Ferreira de Araújo, ainda sob o pseudônimo de Lulu Sênior, mas agora na sessão "Balas de Estalo" retoma o assunto: “[o] high-life cá da terra está a encher-me de desilusões. O diretor da Academia de Belas Artes deixou-lhe um dia da semana para ir ver a exposição e esse dia tem sido justamente o de menor afluência de visitantes.”6 De fato, em 17 de novembro, foi divulgado que a exposição geral de Belas Artes havia sido visitada por 496 pessoas.

De todos os artistas participantes da exposição, José Maria Oscar Rodolpho Bernardelli y Thierry (1852-1931), mais conhecido como Rodolpho Bernardelli, foi quem mereceu a maior atenção. Lulu Sênior fala de suas obras por dois dias seguidos e destaca uma escultura de sua autoria chamada "Vênus Calipígia", imitação de uma peça do Museu Nacional de Nápoles. A escultura causou tão grande impacto entre os visitantes, que ela foi doada por Bernardelli ao atual Museu de Belas Artes e aí está até hoje, ao lado da escadaria principal, junto com a Vênus de Médicis, de autoria do mesmo artista.

Segundo Silva (2005), Bernardelli nasceu no México, mudou-se com sua família para o Rio Grande do Sul e, mais tarde, a convite de D. Pedro II, foi morar na Corte, visto que seus

\footnotetext{
5 Gazeta de Notícias, 1884, p. 02.

6 Idem.
} 
pais se tornaram professores das princesas imperiais. Ingressou na Academia Imperial de Belas Artes em 1870 e, em 1874, naturalizou-se brasileiro.

Tornou-se, em pouco tempo, um escultor renomado pelo seu talento, recebeu vários prêmios internacionais, foi estudar em Roma entre 1877 e 1885 e de lá enviou diversas obras à Academia Imperial de Belas Artes, dentre as quais, a Vênus Calipígia, cópia em mármore do original grego que se encontra no Museu de Nápoles e foi apresentada na Exposição Geral de Belas Artes, de 1884.

Bernardelli retornou ao Brasil em 1885, assumindo o cargo de professor de estatuária da Academia Imperial de Belas Artes.

Na crônica de $1^{\circ}$ de setembro, Machado também comenta o furor causado pela Vênus Calipígia: sob o pseudônimo do zombeteiro Lélio, ele narra as duas visitas que havia feito à Mostra e comenta a satisfação que sentira ao perceber que a população fluminense estava começando a apreciar a arte:

Fui duas vezes à exposição das Belas-Artes e, entre parênteses, estimo ver que é um gosto que se vai desenvolvendo na população.

Da primeira vez, apesar de ser tarde, achei ali cinco pessoas e da segunda, oito ou mais. Cumprimentei o porteiro por esse motivo; ele disse-me que, realmente, a concorrência era bonita, embora devesse descontar um certo número de visitantes, talvez metade, que não passava de pessoas pagas pela Academia para fazer de público. Ganham dez tostões por visita, e há tal que no fim do dia chega a comer os seus quinze ou dezesseis mil réis. ${ }^{7}$

A ironia é evidente, porque o cronista comenta haver pouquíssimos visitantes na Exposição de Belas Artes, o que contrasta com a afirmação "estimo ver que é um gosto que se vai desenvolvendo na população". A galhofa se torna explícita, quando informa que, segundo o porteiro, metade das pessoas ali presente era paga pela Academia para "fazer de público", ganhando "dez tostões por visita".

Chama a atenção de Lélio a Vênus Calipígia de Bernardelli. Tendo a certeza de que o leitor compreende o significado do epíteto, hesita diante da leitora, a quem deseja explicá-lo,

7 Gazeta de Notícias, set. 1884, p. 02 
sem ser deselegante. Por essa razão, recorre à Arte Poética, de Boileau e à Dona Branca, de Almeida Garret:

Calipígia, em bom português, quer dizer uma coisa que só se pode dizer em latim, pela regra de que le latin dans les mots brave l'honneteté. Mas, se a leitora ignora o grego, não é improvável que igualmente ignore o latim, e ficamos na mesma. Recordo-me que há na $D$. Branca um episódio em que isto se explica. A dama está no chão, com a cara escondida, de costas, tendo as roupas violentamente arrancadas, e o poeta exclama, cheio de um arroubo discreto:

...Oh! não as tem mais belas,

Calipígia Vênus! 8

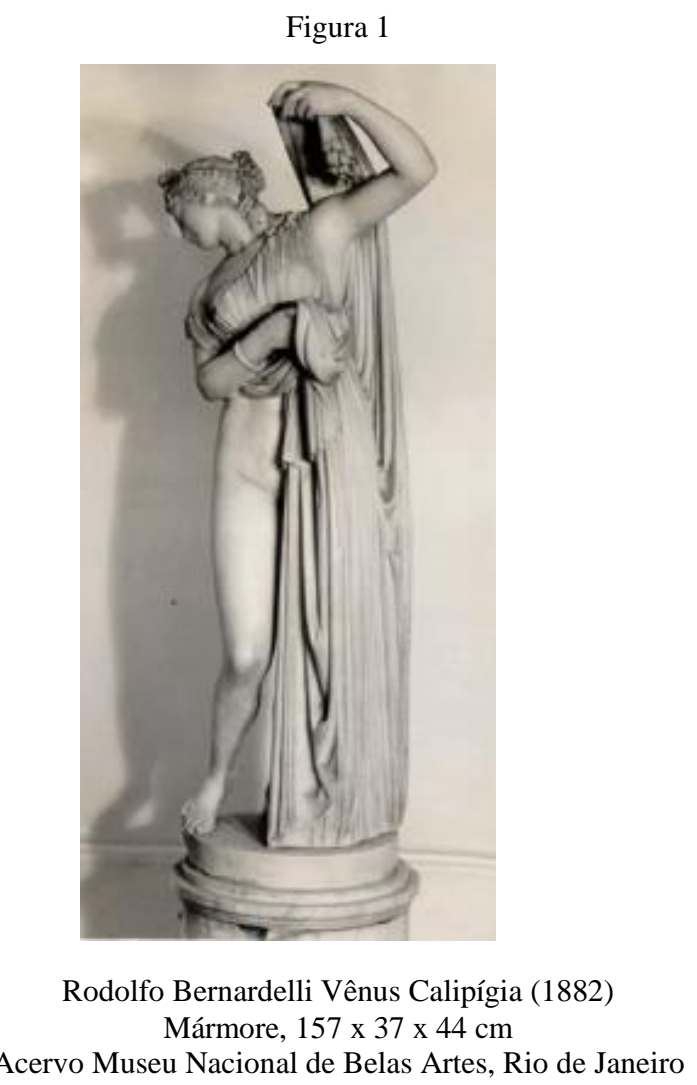

Explicação feita, o cronista narra a sua aventura: o escultor grego que criara a Vênus Calipígia original não havia morrido, mas dormira por volta de dois mil anos na Ilha de

8 Idem. 
Samambaia. Finalmente, havia despertado e viajado de barco para o Rio de Janeiro. Lélio encontrou-o na praia das Marinhas, reconheceu-o e com ele trocou algumas palavras em grego. Como o escultor trazia ainda suas antigas vestes, o cronista o levou à Rua do Ouvidor para vesti-lo "à moderna".

Inserir elementos fantasiosos para comentar um assunto retirado da realidade não é um despropósito se for considerado que existe uma permeabilidade na fronteira entre informação e imaginário, a qual autoriza todas as espécies de reflexos entre o alto e o baixo da página. Assim, a crônica que, originalmente, ocupava o espaço destinado ao folhetim, o rés do chão, dialoga com os acontecimentos que ocupam a parte superior do periódico. Desse modo, o romanesco que se manifesta por meio do extraordinário, da aventura e do sonho, se mescla ao cotidiano, que ocupa o plano referencial, dando ao texto de ficção a garantia da realidade e à informação, o prestígio da literatura. (MOMBERT in KALIFA; REGNIER; THÉRENTY \& VAILLANT, 2011, p. 824)

Convenientemente vestido, o escultor e Lélio deixaram a Rua do Ouvidor e seguiram para a Exposição das Belas Artes, a fim de admirar a cópia feita por Bernardelli da Vênus Calipígia. Ao vê-la, o artista exultou: "ria, ajoelhava, chorava, andava à roda da estátua, dava-lhe beijos de pai, dizia que era uma obra prima, uma inspiração do céu, etc., etc., etc."9 Ao voltarem para a casa de Lélio, o artista grego declarou que iria esculpir uma Vênus Brasileira para agradecer o carinho e a hospitalidade dos fluminenses. Na manhã seguinte, ele se dirigiu à Rua do Ouvidor para procurar uma jovem que lhe servisse de modelo e voltou alguns dias mais tarde, triste e abatido, contando que todas as três mil moças que vira passar pela Rua dos Cem mil paletós, apesar de bonitas, eram aleijadas.

Lélio não compreende a reflexão do escultor, que lhe explica: "Sim, homem, eu desde que saí daqui levava a ideia calipígia na cabeça, para fazer a minha segunda Vênus, e ..."10 O cronista percebe, então, que ele julgava ser um aleijão a anquinha usada pelas mulheres:

Compreendi tudo e expliquei que o que lhe parecia realidade, não passava de um simples acréscimo, por moda. Concordei (para não brigar com ele) que era um adorno horrendo e sem graça. Mas ele não quis crer em nada: achava impossível que, por moda, trouxesse uma senhora toda a mobília consigo e

\footnotetext{
${ }^{9}$ Gazeta de Notícias, set. 1884, p. 02.

10 Idem.
}

Jangada | nr. 16, jun/dez, 2020 | ISSN 2317-4722 
continuou triste e acabrunhado. Felizmente chegou o João Velhinho (são contemporâneos) e lá os deixei em casa, conversando sobre a guerra de Tróia.

Segundo Mello (2018), anquinhas e creolinas eram os trajes inferiores que as moças usaram durante quase todo o século XIX. Feitas de crina de cavalo, barbatanas de baleia e, posteriormente, de metal, elas passaram a ter dimensões cada vez mais exageradas, provocando não apenas desconforto ao caminhar e sentar, mas até mesmo graves acidentes como aqueles ocorridos com mulheres que morreram queimadas em incêndios por não conseguirem passar pela porta e sair.

A indignação diante do adorno é tão grande, que o periódico Gryphus, dois anos depois da crônica escrita por Machado, traz o artigo “A Moda” assinado por Gil Blas em que a postura das mulheres que seguem a voga é criticada:

Dentre os ridículos, todos postos em moda pelas senhoras, destaca-se, avulta, ressalta, sobrepuja a moderna anquinha, ou que mais acertado e mais sujo nome tenha, com que elas pretendem adornar-se. É a esse enfeite (verdadeiro enfeite de gralha sem que seja de penas de pavão) que eu chamo aleijão. ${ }^{12}$

Para Gil Blas, o adereço é indecente, porque chama a atenção para um ponto do corpo feminino que deveria ser resguardado; além disso, é evidentemente falso: "[a]creditarão acaso que haja quem creia que semelhante apêndice é de carne? E se o fosse, seria bonito? Haveria Calipígia possível?"13 Observe-se que, como Machado, o articulista da Gryphus serve-se da palavra "aleijão" para tratar do uso das anquinhas, bem como do epíteto Calipígia.

As ilustrações abaixo mostram alguns moldes publicados pela revista A Estação, Jornal Ilustrado para a família (1879-1904), periódico fluminense de publicação quinzenal que se dividia em duas partes, o "Jornal de Modas" e a "Parte literária". Embora Machado de Assis tenha publicado vários contos no espaço reservado à literatura, é o espaço da moda que interessa aqui, pois graças aos moldes aí publicados, é possível verificar que as anquinhas foram ganhando proporções cada vez maiores, conforme a passagem dos anos.

\footnotetext{
11 Gazeta de Notícias, set. 1884, p. 02.

12 Gryphus, revista literária, humorística e ilustrada, nov. 1886, p. 43. 13 Idem.
} 
Figura 2

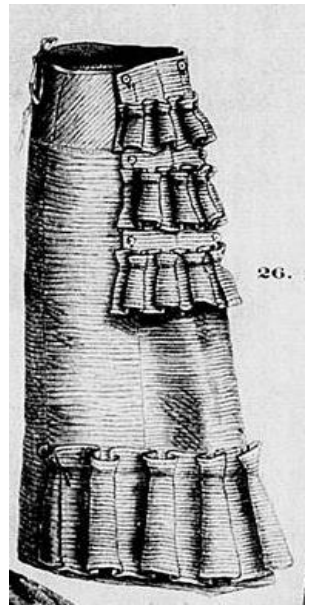

A Estação, fev.1879, p.3
Figura 3

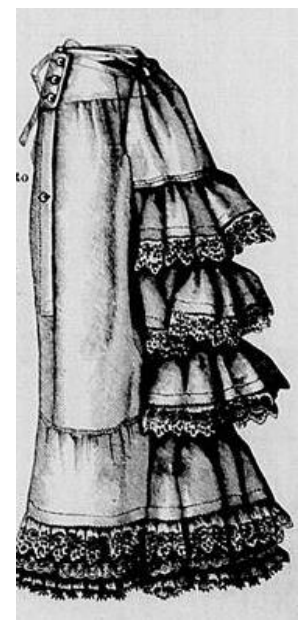

A Estação, abr.1882, p.4
Figura 4

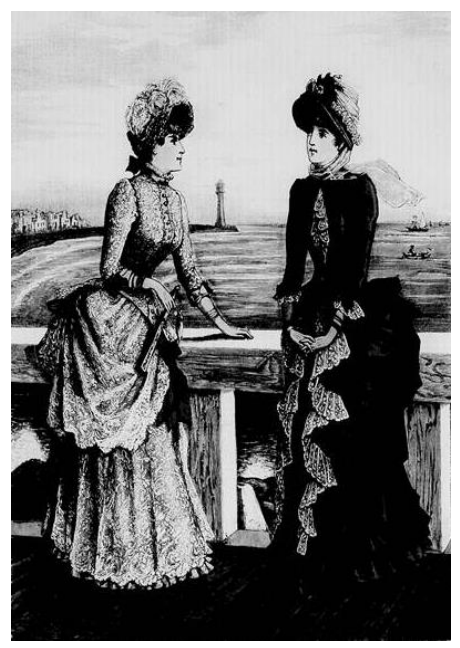

A Estação, agosto 1884, p. 9

Em 1889, a mesma revista $A$ Estação que, anos antes, promovera a difusão do adorno feminino decretaria: "Não se usam mais anquinhas nem almofadas para levantar o puff. Dois aros sobre 35 e 40 centímetros, é tudo o que a moda permite". ${ }^{14}$ Os vestidos tornar-se-iam, a partir de então, menos armados.

É curioso observar que o articulista Gil Blas também faz referência à Vênus Calipígia ao comentar o adereço, o que permite confirmar a associação feita na crônica machadiana entre a escultura e as anquinhas.

No meio de toda a discussão, surge a figura de Boileau Despréaux para ajudar o cronista a definir o epíteto "calipígia": como certas palavras são difíceis de explicar às damas, o cronista recorre ao teórico do classicismo francês, visto que le latin dans les mots brave l'honnêteté.

Por meio de outras crônicas, é possível verificar ser a obra do escritor francês conhecida de Machado; há até mesmo um exemplar de Oeuvres Poétiques de Boileau na Biblioteca de Machado de Assis (MASSA, 1961): não se trata apenas, portanto, do conhecimento obrigatório da Arte Poética, mas da leitura atenta dos poemas do escritor francês, uma vez que a presença de Boileau se manifesta a partir de 1861 nas crônicas machadianas e

14 A Estação, fev. 1889, p. 1.

Jangada | nr. 16, jun/dez, 2020 | ISSN 2317-4722 
ele será evocado até mesmo em 1894, coincidentemente quando o cronista comenta a inauguração da estátua do General Osório, também criada por Bernardelli.

Como se vê, quando citou Boileau em 1884, Machado de Assis o conhecia havia muitos anos e sabia ser sua intenção criar uma obra didática que reunisse e sistematizasse sua "doutrina" esboçada nas Satires littéraires: o ideal clássico.

Boileau pretendia fazer uma reflexão a respeito do que já fora escrito, coligir “[...] o essencial de uma doutrina literária e de regras, havia muito formadas e adotadas, que ainda não tinham sido apresentadas em conjunto num grande texto"15 (RIEGERT, p. 08, trad. minha)

O tema não era, portanto, original, mas era a primeira vez que essas ideias eram coligidas em versos. $\mathrm{O}$ autor justificou sua atitude, afirmando querer atingir não somente os especialistas em poesia, mas também o grande público e, para isso, seria preciso evitar um tom muito pedante e rebuscado, buscando uma linguagem agradável e artística. Na verdade, Boileau fez de seu livro um clássico da literatura que, durante séculos foi bastante respeitado como lei a ser seguida.

O livro é dividido em quatro cantos que se referem a todas as formas de poesia: os gêneros menores, maiores, o poema épico, a comédia e a tragédia. A citação presente na crônica de Lélio pertence ao Canto II, em que Boileau se ocupa dos gêneros menores como a elegia, a ode, o soneto, a sátira e as baladas. $\mathrm{O}$ escritor francês destaca nessa parte a importância do equilíbrio e da moderação e sugere que Teócrito e Virgílio sejam tomados como exemplos, pois ambos fogem dos excessos a serem evitados. Ele afirma que Juvenal exagera nas hipérboles, mas sua obra está repleta de verdades e belezas sublimes, o que torna perdoáveis os exageros por ele cometidos. Em seguida, trata da obra de Mathurin Régnier, célebre por seus poemas satíricos. Boileau comenta que Régnier tinha um velho estilo repleto de novos encantos e que ficava feliz se os seus discursos, temidos pelo leitor casto, traziam as marcas dos lugares por ele frequentados ou se atormentava com regularidade os ouvidos pudicos com o som atrevido de suas rimas cínicas. Na sequência, encontram-se os versos citados por Machado em sua crônica:

Le latin, dans les mots, brave l'honnêteté,

Mais le lecteur français veut être respecté;

Du moindre sens impur la liberté outrage,

15 No original: "l'essentiel d'une doctrine littéraire et de règles, depuis longtemps formées et adoptées, qui n'avaient cependant pas encore été présentées dans un grand composé d'ensemble". (RIEGERT, p. 08) 
Si la pudeur des mots n'en adoucit l'image (BOILEAU, 1972, p. 60)

O que significa, numa tradução livre, que o latim nas palavras ofende a castidade, mas o leitor francês quer ser respeitado; a liberdade do menor sentido impuro causa indignação, se o pudor das palavras não suavizar a imagem. O "latim" aqui deve ser compreendido como uma metonímia para autores da Antiguidade, como Horácio, Cátulo e Juvenal que se serviam de um vocabulário por demais explícito para o gosto dos franceses. Em carta a Madame d'Épinay, o Abbé Galiani reclama desse pudor exagerado: ao receber uma tradução da obra de Juvenal, ele lamenta a perda do tom original, pois uma sátira tem um estilo gracejador e até mesmo picante. E conclui: "não se deve traduzi-la com decência e gravidade; mas a decência mata os franceses" (GALIANI, 1881, p. 359, trad. nossa). ${ }^{16}$

No mesmo sentido, ao tratar das Sagradas Escrituras, Espinosa assim explica a prática dos autores antigos:

$\mathrm{Na}$ verdade, os autores antigos, porque não tinham qualquer malícia, chamavam as coisas pelos nomes próprios, sem rodeios palacianos. Mas quando passou a reinar a malícia e a luxúria, aquilo que os antigos diziam sem obscenidade passou a ser tido por obsceno. (ESPINOSA, 2004, p. 267)

Trata-se, portanto, de uma discussão acerca do uso de palavras cruas e explícitas na Literatura. Para Boileau, o importante era a razão e o bom senso. O artista deveria buscar o belo e o verdadeiro para atingir a perfeição e, acima de tudo, agradar ao público. Isso exigia tempo, dedicação e humildade para fazer várias correções, retirando de seu texto, inclusive, palavras que pudessem ofender o leitor ou fazê-lo ruborizar. Ao citar Boileau, Machado de Assis envolve seu discurso em uma atmosfera clássica, para esclarecer um problema cômico: ele expressa a preocupação de não constranger seu público feminino declarando não possuir a intenção de fazê-lo enrubescer ao explicar-lhe o significado de calipígia. O cronista carioca, guardadas as diferenças de época, aproxima-se do escritor francês em alguns aspectos. O jovem escritor brasileiro já fazia muitas afirmações em seu Instinto de Nacionalidade que poderiam vir a

\footnotetext{
16 No original: "On ne doit pas la traduire avec décence et gravité; mais la décence tue les Français". Disponível em https://gallica.bnf.fr/ark:/12148/bpt6k63618709/ Acesso: 18/05/2020.
} 
lembrar L'Art Poétique. Para Machado de Assis, por exemplo, "o sublime é simples" e a simplicidade deve ser buscada pelos poetas desejosos de pintar "as magnificências da vegetação". (ASSIS, 2008, p. 1.206)

O discurso de Lélio reforça a presença do ideal clássico: o colaborador das "Balas de Estalo" não só cita Boileau como, ainda na mesma crônica, relata a extraordinária visita do escultor grego que teria criado a Vênus Calipígia original e sua intenção de esculpir uma Vênus Brasileira, para que o mundo moderno também pudesse contemplar uma obra de rara beleza.

Toda essa atmosfera clássica é criada a fim de preparar o leitor para o assunto principal da crônica, que está em seu desfecho: o uso de anquinhas. A moda dos vestidos com armação é discutida e reprovada por Lélio e pelo escultor grego: "era um adorno horrendo e sem graça"17. O vocabulário usado por Lélio mescla o popular ao erudito, o que confere ao seu discurso uma aparência atual e irreverente: "estou em maré de coisas más", "referi-lhe a bulha que sua Vênus fazia", "o alvoroço do pobre diabo".

A presença de Boileau dá à crônica uma base clássica, confirmada pela visita do escultor grego. A antiguidade se opõe à modernidade da Rua do Ouvidor. A cautela do cronista o aproxima do escritor francês: ele utiliza um vocabulário bastante elaborado e sua intenção é agradar, não chocar. Entretanto, ao trazer o autor da Vênus Calipígia para o Brasil, tantos anos depois, o cronista rompe com um dos preceitos mais caros ao autor de L'Art Poétique: a verossimilhança: Machado dá as costas para a razão e o bom senso de Boileau e insere o seu estilo, a sua capacidade criadora que, respeitando determinadas normas e padrões, rompe com todas as regras e institui a sua própria lei: tudo é possível, se feito com inteligência e criatividade. O leitor seguirá seus passos, extasiado, às vezes perdido, mas sempre fiel à mescla cômica que caracteriza o texto.

O passado e o presente, Grécia e Rio de Janeiro, Boileau e Lélio todos convivem harmoniosamente nesta crônica, graças à porosidade que se estabelecia no século XIX entre imprensa e literatura, porosidade esta que significava uma contaminação recíproca entre a "matriz literária da imprensa" e a "matriz midiática"; ou, mais especificamente, entre literatura e jornalismo. A contaminação ocorria a ponto de se afirmar a existência de uma "ficcionalização do jornal" (THÉRENTY, 2007, p.30).

Os termos são explicados por Thérenty, segundo a qual a matriz mediática se caracterizava pela periodicidade, o efeito de rubrica, a coletividade e a atualidade, enquanto a

17 Gazeta de Notícias, set. 1884, p. 02.

Jangada | nr. 16, jun/dez, 2020 | ISSN 2317-4722 
matriz literária era definida por conter em seu bojo a ficção, a conversa, a ironia e a escrita intimista. A crônica estaria no cruzamento entre ambas as matrizes, visto pertencer ao gênero jornalístico.

Ao tratar de costumes culturais do século XIX, Machado de Assis conseguiu reunir o autor de Art Poétique, o escultor da Vênus Calipígia e o high-life carioca. Sob o pseudônimo de Lélio, aproveitou para repreender o público indiferente a manifestações artísticas e, muito educadamente, demonstrar seu desagrado em relação ao uso das anquinhas. Dessa forma, criou um texto híbrido que retratava a atualidade do período e, ao mesmo tempo, permitia a inserção da criatividade do ficcionista.

\section{REFERÊNCIAS BIBLIOGRÁFICAS:}

ASSIS, Machado de. História de quinze dias. In: COUTINHO, Afrânio (org.). Machado de Assis Obra completa. Rio de Janeiro: Nova Aguilar, 1997. p. 344.

ASSIS, Joaquim Maria Machado de. Crônicas de Lélio. org. R. Magalhães Jr., Rio de Janeiro: Ediouro, Coleção Prestígio, 198-.

ASSIS, Machado de. Obra completa em quatro volumes. v. 3. Rio de Janeiro: Nova Aguilar, 2008.

BOILEAU. L'Art poétique. Paris, Larousse, 1972, p. 58-60.

CALLIPO, Daniela. As Balas de Estalo de Machado de Assis. Todas as Letras, São Paulo, volume 10, n. 2, p. 19-24, 2008.

ESPINOSA, Baruch. Tratado Teológico-Político. Lisboa: Imprensa Nacional - Casa da Moeda, 2004, p. 267.

GALLIANI . Lettres de l'Abbé Galiani à Madame d'Épinay. Paris: G. Charpentier, 1881, p . 359. Disponível em https://gallica.bnf.fr/ark:/12148/bpt6k63618709/ Acesso: 18/05/2020.

GAZETA DE NOTÍCIAS. Rio de Janeiro, 1885.

GUIMARÃES, Hélio de Seixas. Introdução. In: Os leitores de Machado de Assis: o romance machadiano e o público de literatura no século 19. São Paulo: Nankin; Edusp, 2004. KALIFA, Dominique; RÉGNIER, Philippe; THÉRENTY, Marie-Ève; VAILLANT, Alain. (orgs.) La civilisation du journal: une histoire de la presse française au XIXe siècle. Paris: Nouveau Monde, 2011. 
MASSA, Jean-Michel. La Bibliothèque de Machado de Assis. Rio de Janeiro: Revista do Livro, 1961.

MELLO, Aglair Nigro. Traje interior no século XIX: construção passo a passo de cinco estruturas. Dissertação de Mestrado. São Paulo, 2018.

MICELI, Sérgio. Poder, sexo e letras na República Velha. Estudo clínico dos anatolianos. São Paulo: Perspectiva, 1977.

Silva, Maria do Carmo Couto da. A obra Cristo e a mulher adúltera e a formação italiana do escultor Rodolfo Bernadelli. Dissertação de Mestrado Campinas, IEL -UNICAMP: [s.n.], 2005. SODRÉ, Nelson Werneck. A história da imprensa no Brasil. Rio de Janeiro: Civilização Brasileira, 1966.

THÉRENTY, Marie-Ève. La Littérature au Quotidien: Poétiques journalistiques au XIX siècle. Paris: Éditions du Seuil, 2007. 